\title{
The Non-Cooperative Sadian Pragmatics Principle
}

\section{in Communication}

\author{
Patrick Sadi Makangila (First and corresponding author) \\ (MA, a Ph.D. candidate at the Central China Normal University) \\ E-mail: 3159632708@qq.com \\ Yesdauletova Sabira \\ (MA, a Ph.D. candidate at the Central China Normal University) \\ E-mail: sabira.askarovna@mail.ru
}

Received: March 23, 2020 Accepted: April 7, 2020 Published: April 8, 2020

doi:10.5296/jsel.v8i1.16812ＵRL: https://doi.org/10.5296/jsel.v8i1.16812

\begin{abstract}
This paper explores another way of presenting the non-cooperative principle in communication in pragmatics with practical illustrations from Chinese language and English, although this principle could be observed in almost all languages and dialects of this world. This study is based on the Cooperative Principle elaborated by Herbert Paul Grice which obeys to the four maxims of conversation: the maxim of quantity, quality, relation, and manner. The study hypothesizes that there are several ways in communication where the principle of non-cooperative could be found, not just in the way that other scholars have been presenting it, and this non-cooperative principle is called the Non-Cooperative Sadian Pragmatics Principle in Communication. This study is based on introspection rather than data with theoretical research work based on Grice's Cooperative Principle, then forwarding illustrations from daily conversation.
\end{abstract}

Keywords: cooperative principle, non-cooperative principle, Grice's maxims, Pragmatics 


\section{Introduction}

This study in Non-Cooperative Principle in Communication with reference to $\mathrm{CP}$ (which is the abbreviation of Cooperative Principle), the principle elaborated by Herbert Paul Grice British-educated and Oxford Philosopher of Language and the Maxims of Conversation. The main purpose we use the language is for communication, and this imply exchanging of information which could be expressed also implicitly. Grice's work on the nature of meaning has influenced the philosophical study of semantics and his theory of implicature is among the most important and influential contributions to contemporary pragmatics.

According to Grice, in the daily conversations, people do not usually say things directly but tend to imply them. The cooperative principal is a norm governing all cooperative interactions among humans, in other term is a basic underlying assumption we make when we speak one to another. We try to cooperate with one another to construct meaningful conversation, because if the speakers do not cooperate, it almost impossible to have an interesting/meaningful conversation, sometimes people can deliberately refuse to cooperate, especially during the trial, people are afraid of relying on some facts which could implicated their closer friends and relatives. Herbert Paul Grice suggests that when we are making our contribution, we have to make it such as it is required, by the accepted purpose or direction of the talk exchange in which we are engaged.

The cooperative principle entails that language users in interactions obey four maxims. They are known in the field as 'quality', 'quantity', 'relation' and 'manner'. The researchers spend a substantial textual space to elaborate Gricean theory by initiating to present the past literature under the same topic and directly related topics.

Some previous researchers have concluded that the Cooperative Principle is also simply a device to explain how people arrive at meanings. Some have compared Leech's 'Politeness Principle' with this. In this field of research, a substantial amount of work remains to be done to narrow the gap between universal and empirical pragmatics, the analysis of strategic discourse points in a direction that may well prove both stimulating and fruitful.

This study remains with its original contribution to the main discipline of Linguistics and particularly a new dimension to Sociolinguistics as it has much directed towards the social practice. They also have established a strengthened relationship between different disciplines to form a new framework for interdisciplinary studies. Particularly citing from Leech and Thomas concluded that pragmatics is at a crossroads between developing a cognitive theory of communication and a social one. The authors' strong stance is that the cognitive theory cannot be developed unless it takes on a social perspective and the language use always takes place in a situational context and the context is social. This conclusion has further been strengthened by citing some research findings by Hoberland and Mey from a study conducted in 1977. 


\section{Aim and Hypotheses}

This paper seeks to explore the different ways of expressing the non-cooperative in daily life conversations. Therefore, after briefing the cooperative principle introduced by Herbert Paul Grice, the main objective of this research paper is to come up with several ways of manifestations of the non-cooperative principle in communication by examining the correlations between participants' socioeconomic interests, their social identities, the social and situational powers they possess and their expectations about activities by checking the other potential values apart from the conversation of the pragmatic theory by Grice. The main objective which could be clarified in other words as matching the non-cooperative Gricean pragmatics principle in communication with the approach of discourse analysis in the daily language. Taking the main theme as non-cooperation in communication, the researcher attempts to re-evaluate the Pragmatic Theory of Herbert Paul Grice in this research in several ways, several languages, and dialects.

\section{Literature Review}

Grice's Cooperative Principle has been a central and controversial theme in pragmatics. A major source of controversy associated with the CP is that the term "cooperation" is open to different interpretations. In order to develop a thorough understanding of the concept, the $\mathrm{CP}$ and conversational implicatures should be studied within the context of Grice's work (Hadi, A. 2012, p. 69).

Arezou Sobhani \& Ali Saghebi (2014, p. 92) from a conversation between a male psychotherapist and his patients during therapy sessions, after analyzing their language by means of conversational implicature and the occurrences of the violation of Cooperative Principle, they come to the conclusion that the recognition of conversational implicature is essential for the understanding of the non-cooperative attitudes of the speakers and their violation of one or more Cooperative Principle maxims. Moreover, it was clear that the message people intend to convey is not wholly contained within the words they use, but it is also dependent on how hearers interpreting the message taking into account context and implicated meaning. Finally, there were instances when the purpose was to intentionally miscommunicate within this sophisticated social context.

H. P. Grice (1989, p. 41) suggests that the Cooperative Principle and some subordinate maxims are standardly (though not invariably) observed by participants in a talk exchange. Srikant K. Sarangi and Stefaan Slembrouk (1990, p. 119) Pay foremost attention on the cooperative principle (Referred as CP) by defining it as; make your conversational contribution such as is required, at the stage which it occurs, by the accepted purpose or direction of the talk exchange in which you are engaged.

Ladegaard (2008; quoted in A. Hadi, 2013, p. 70) states that instead of applying the traditional view to language and communication offered in Pragmatics, in which human interaction is viewed as naturally deficient and problematic, a broader view should be considered. He mentions that Grice is extremely biased towards cooperation. Grice's 
assumption is that people communicate logically, and all of them attempt to be "good" communicators.

According to A. Hadi (2013, p. 69) Grice's work on the Cooperative Principle led to the development of "pragmatics" as a separate discipline within linguistics. However, the interpretation of the $\mathrm{CP}$ is sometimes problematic because Grice's technical term "cooperation" is often confused with the general meaning of the word cooperation.

Herbert Paul Grice (1969, p. 147) recognizes that within the range of uses of the word "mean" which are specially connected with communication (uses, that is, of the word "mean" in one or another of what I have called "nonnatural" senses), there are distinctions to be made. Ladegaard (2008; quoted in A. Hadi, 2013, p. 70) while analyzing conflicts with Grice's position, he claims that "human interaction may be irrational and illogical, and that resistance and non cooperation may be adopted as the preferred discursive strategy, and that interactants seem to try their best to be 'bad' communicators."

Srikant K. Sarangi and Stefaan Slembrouk (1990, p. 119) spend a substantial textual space to elaborate Gricean theory by initiating to present the past literature under the same topic and directly related topics, they make an important evaluation on Gricean theory is about conversation although it clearly has traits of a more general theory of information exchange in communication. According to them, politeness is a deviation from the Cooperative Principle is quite different from Leech's formulation of a Politeness Principle as a necessary compliment to the CP (1990, p. 122). Srikant K. Sarangi and Stefaan Slembrouk have jumped into another preliminary conclusion that the use of $\mathrm{CP}$ as a device for explaining how language users arrive at meaning focuses us into a position where one has to postulate a mutually accepted and defined content for the Gricean maxims, and the risk is indeed that the institutional definitions are given an absolute, scientific status (1990, p. 132).

Following the previous observations in preliminary conclusions, Srikant K. Sarangi \& Stefaan Slembrouk (1990, p. 139) have come in to the second important observation in which a notion of cooperation in the abstract cannot be taken to presuppose the simultaneous observance of the maxims of quality, quantity, relation and manner.

The study of A. Hadi (2013, p. 71), although being based on introspection rather than data, and does not consider interpersonal factors, stipulates that Grice's work faces major limitations, it is still at the centre of the disciplines of pragmatics and the important role it plays in this field cannot be denied. However we should be careful interpreting what is meant by "cooperation" in Grice's CP. His notion is different from the everyday notion of cooperation.

\section{Research Method}

This study is based on introspection rather than data., with theoretical research work based on the briefing of H.P. Grice's cooperative principle, then forwarding illustrations from daily conversation. 


\section{Discussion and Concluding Remarks}

According to H.P. Grice the language users in their conversations must rely on these four elements Quantity - Quality - Relation - Manner, that he calls four maxims. Maxim by definition is a phrase or saying that includes a rule or moral principle about how you should behave. Grice points out examples of implicatures or three categories of cases in which a maxim is flouted, clashed or violated. In the first case, the speaker cannot accomplish the maxim due to certain effect. In a clash of maxims, the speaker is not able to complete the maxim in order to respect the listeners, and in the last case, there is hidden non-cooperation and the speaker can be misled (Grice, 1989: p. 30; quoted in A. Hadi, 2013, p. 70).

*The Maxim of Quantity: The interlocutor has the responsibility to make his contribution as informative as is required (which means that the answer must be for the current purpose of the exchange) and the information can not be more informative than is required.

*The Maxim of Quality: The interlocutor has to try to make his contribution one that is true. Here the interlocutor should not say what he believed to be false, or which he lacked adequate evidence. Srikant K. Sarangi \& Stefaan Slembrouk also have posited that the content of Gricean maxims derives from the pragmatic context and can only be explained by recourse to an examination of the societal dimensions of the discourse. Before coming to the findings in more concrete terms, they have made two more prior- observations: The contents of the maxims of information exchange, and the presumptions which interlocutors make about one another as to the likelihood of a particular kind of informativeness are indeed very often asymmetrical. Attributes such as (ir) rational, (in) efficient, human benevolence, ethical, moral, etc., reflect the speaking subjects' social perceptions and backgrounds vis-à-vis goals, interests, activity types, etc.

*The Maxim of Relation: The answer of the interlocutor needs to be relevant.

*The Maxim of Manner: The interlocutor's answer needs to be clearly expressed and easily understood, by avoiding obscurity of expression and ambiguity, by being brief while avoiding unnecessary prolixity, and finally by being orderly. These maxims do not prescribe how one should talk, but explain the listeners' assumptions regarding the way speakers do talk (A. Hadi, 2013, p. 69).

Let's talk about the four maxims mentioned by Herbert Paul Grice in his CP theory in details:

*The Maxim of Quantity: refers to the information that the language users suppose to provide, this information must be sufficient but not excessive. No need to go over people's expectations. 


\section{Macrothink

H.P. Grice concerning the " Maxim of Quantity" Stipulates that the language users shall make their contribution as informative as is required. Do not make your contribution more informative than is required.

The Gricean theory is proposed to amend with some social aspects and the Non-Cooperative Sadian Pragmatics Principle in Communication, this theory tries to demonstrate how the non-cooperative principle could be found in many languages and dialects in other ways, rather than those previously discussed by other scholars. The Non-Cooperative Sadian Pragmatics Principle in Communication includes the understanding ability of the interlocutor 2, his willingness to have a conversation which could imply answering question by question if he really does not need to have a conversation at all. Therefore taking into account the relationship between language and use, sentence meaning and speaker meaning, semantics and pragmatics is highly considered in the Non-Cooperative Sadian Pragmatics Principle in Communication. The following is a concrete example for the maxim of quantity, how people suppose to answer the question in the light of the maxim of quantity.

\section{Example 1:}

A: Helen, what is Labor Day and do we celebrate it? Why

B: Labor Day is celebrated on the first Monday of September. It is a day set aside to honor the working people of the United States and to give them an official day of rest.

Now, let's take one example which is not obey to the maxim of quantity.

Example 2:

A: Teacher: Peter, do you return the homework?

B: Peter: Sir, you know! I am a hard worker student, you can see that when you confront my transcript with other students' transcript, since the beginning of this academic year, I never missed even a single class, but because of certain things in my life which are not going smoothly, maybe due to the birth of my first son, he cries every night, and I can not sleep well. Actually I can not finish my return my homework, but I will do my best to return it as soon as I can. So I do not return my homework.

*The Maxim of Quality: makes allusion to the information that the language users suppose to provide, this information must be true. According to H.P. Grice, the language users shall make their contribution one that is "true", by avoiding to say what they believe to be false, and also by avoiding to say for what they lack adequate evidence. 
Following is an example which not obey to the "Maxim of Quality" 2020, Vol. 8, No. 1

Example 3:

\section{A: You danced very well.}

B: Thank you. But I may not be as good as you are.

From the example above, there is something interesting to retain in the western countries' culture, if somebody makes a compliment to you, it means that the person is quite sure about what he is complimenting you, so you just need to say thanks otherwise, he will feel embarrassed. While in the eastern countries, particularly in China, you will need to reject the compliment although you could be happy to listen to such compliments, if you do not reject the compliment, then you will be treated as somebody who is not humble.

*The Maxim of Relation: consist to the information that the language users suppose to provide must "Be relevant". The language user should "Make his contribution relevant".

The following example obeys to the "Maxim of Relation".

\section{Example 4:}

\section{A: When did you come to China?}

B: Four years ago.

The relevance information is the most important, and stand at the highest level. In the conversation, the answer can be precise but if it is not appropriate or related to the question, this answer is useless.

*The Maxim of Manner: consist to the information that the language users suppose to provide must be perspicuous and specific; be clearly expressed and easily understood by avoiding obscurity of expression, ambiguity, unnecessary prolixity and the language user must be orderly.

\section{Case study}

The CP, principle elaborated by Herbert Paul Grice, Cooperative principle, with the four maxims that the language users must rely on in their conversations (1957): maxims of quantity, 
quality, relation and manner, these are not what we ought to be, but what actually happened in conversation.

Besides the CP elaborated by Herbert Paul Grice, we can add a principle that could be an antagonist, it is the NCP which is the Non-Cooperative Principle. In some countries especially in the Democratic Republic of Congo, in daily conversations, many people answer the question by another question. We are going to focus on the particular cases which are quite different from their formal conversations.

\section{Example 5:}

\section{A: Where are you going?}

B: What do you want to know? If I have to go somewhere, I should need your authorization right?

Example 6:

A: How old are you?

B: I'm older than you. Don't you think so?

This kind of NCP (non-cooperative principle) considered in this paper as a Non-Cooperative Sadian Pragmatics Principle in Communication is frequently observed among young people, among persons from the same social class, same generation. It could even become like a reflex, reacting or answering to the question in a very quick way, sometimes even without thinking about it, just answering with a certain spontaneity, unconsciousness. This way of acting can be considerate as an anticipation to the second question, and it'll not be taken as Non-Cooperative Principle.

In China, it can be observed among people with a lot of responsibility, or the persons who do not have enough time to talk, when people greet them, they just go directly to question without even saying Hi!

\section{Example 7:}
A: 您好! Nín hăo! (Hello!)
B: 怎么了? Zěnme la? (What's wrong?) 


\section{Macrothink}

Example 8:
A: 您好! Nín hăo! (Hello!)
B: 有什么事? 直接说。Y̌̌u shé me shi?? Zhijiē shuō. (What's the matter? Speak directly.)

Schema

Interlocutor 1. $Q$ (question) $\rightarrow \leftarrow$ Interlocutor 2. $Q$ (question)

Interlocutor 1. Q (question) $\rightarrow \leftarrow$ Interlocutor 2. $Q$ (wrong answer)

From the schema above, it can be seen black and white that the Non-Cooperative Sadian Pragmatics Principle in Communication does not obey to the four maxims of the Cooperative Principle elaborated by H.P. Grice and other Non-cooperation principle in communication.

Here are the practical cases to justify the previous statement. The maxim of quantity, compared to the Non-Cooperative Sadian Pragmatics Principle in Communication, here the contribution of the interlocutor 2 is not informative, sometimes the interlocutor 2 provides zero information by retorquing with another question. The following example will help us to figure out.

\section{Example 9:}

A：你怎么啦? Nǐ zěnme la? (What's the matter with you?)

B：关你什么事? Guān nǐ shénme shì? ( It's none of your business.)

In this example, we can see how the second interlocutor is not cooperative at all, but from some perspective, he could be considered even more cooperative than the interlocutor who can not say even a single word. Some interlocutors could provide an answer that is much more than the expectation, sometimes the answer is just based on speculation, instead of the authentic information.

Example 10:
A: How old are you?
B: I am old than you. 


\section{Macrothink}

We can consider this answer as Sadian's non-cooperative principle because the interlocutor 2 does not answer the question with the appropriate answer. When someone asks you the question to know how old are you, you just need to say your age instead of making a claim by presuming to be older than him what could be considered also as a kind of speculation.

In the following example, the interlocutor is not giving a precise answer.

Example 11:

A: Are we going to the pic-nick today?

B: Possibly! Probably!

By failing to say "yes" or "no", the interlocutor 2 is not cooperating in 100 percent, because "Possibly" means that they may go or they may not go, while "Probably" means that there is a good chance to go to the pic-nick today. This, is considered as non-cooperative answers in Sadian's non-cooperative principle in communication.

The maxim of quality: according to H.P. Grice's CP, the Interlocutor has to make his contribution one that is true, while in the NCP, the Interlocutor could sometimes provide zero information, so noway to categorize his answer.

Example 12:

A: 您是最棒的! [nín shì zuì bàng de!] (You are the best!)

B：不敢当！我可是比不上您。[bù găn dāng! wǒ kě shìbì bù shăng。]

(I really don't deserve this. I can't compare myself with you.)

Here the interlocutor 2, knows that he is better than the interlocutor 1, but he still says that he can not compare himself with his interlocutor, because his interlocutor is better than him, while it is not true.

Now let's see it under Sadian's non-cooperative principle in communication. We will keep the same example and try to modify the answer or the contribution of the interlocutor 2 in the conversation. 


\section{Macrothink}

Example 13:

\section{A: 您是最棒的。[nín shì zuì bàng de。] (You are the best) \\ B: 别拍马屁了。[bié pāi mă pì le。] ( stop sucking up.)}

In this conversation, we can see how the interlocutor 2 interrupts the interlocutor 1 by telling him to stop sucking up, and it is obvious that the communication did not continue.

The maxim of relation, here the contribution provides by the interlocutor must be relevant. As it can be observed in the examples above, in my NCP the interlocutor answers to the question sometimes in the vaguely or broadly, or just replying by asking the same question to the interlocutor 1 .

Example 14:

A: where are you going?

B: I am going somewhere.

Here the interlocutor 2 tries to answer regarding the asked question, so the answer still relevant but not so precise, because in the question to know where you are going, the answer should be the name of the place or a destination maybe. Therefore according to Sadian's non-cooperative principle, the answer of the interlocutor 2 is considered as a non-cooperative answer.

The following example will show us how the answer could be relevant while being considered as non-cooperative answer.

Example 15:

A: Where are you going?

B: You, where are you going?

Answering a question by a question could seem to be relevant, but as this interlocutor did not answer the question, so we can consider is answer as a non-cooperative answer according to Sadian's non-cooperative principle in communication.

In the maxim of manner, the contribution of the interlocutor must be brief (avoid unnecessary prolixity), the interlocutor has to avoid obscurity of expression, he must be orderly, so clearly 
expressed and easily understood, these are what is required to the interlocutor, while in the Sadian's non-cooperative principle in communication, the interlocutor is a bit brief but without providing the exact information.

Example 16:

A: What's up!

B: There is nothing in the sky, are you seeing something in the sky or you are just asking me if I am doing great? Please, do not mention it!

Herbert Paul Grice admits that in some cases the conventional meaning of the words used to determine what is implicated, besides helping to determine what is said (1989, p. 25). This example could demonstrate what H. P. Grice says while considering the criteria for judging linguistic intentions very like the criteria for judging nonlinguistic intention is to show that linguistic intentions are very like nonlinguistic intentions (1957, p. 387-388).

This example is considered as non-cooperative if we have to focus on the answer of the interlocutor 2, when he says "do not mention it". therefore we can observe the Sadian non-cooperative principle in communication.

\section{Final Conclusion and Suggestion by the Authors}

The final remark of this paper focuses more on the requirement of interdisciplinary. It has some aspects with language and society which could be studied in Sociolinguistics as the Non-Cooperative Sadian Pragmatics Principle in communication take more elements into consideration. Sometimes, scholars fail to give a correct conclusion while the interlocutor 2 fails to get the meaning, and answers in the wrong way, then the provided information is considered wrongly as a Non-cooperative. B. Bultinck (2005, p. 2) thinks that the question of which meanings are "semantic" and which should be relegated to the "pragmatic" sphere became the central consideration and numerals were often appropriated for theoretical purposes and the independent investigation of their meaning became subordinate to their integration into a wider framework that tried to account for the relationship between language and use, sentence meaning and speaker meaning, semantics and pragmatics. Therefore, the Non-Cooperative Sadian Pragmatics Principle in Communication takes into account the understanding ability of the interlocutor 2 and the willingness to have a conversation with the interlocutor 1 . 


\section{Recommendations}

This research recognizes multiple ways of expressing the non-cooperative principle in communication besides the different principles elaborated by some scholars including the Non-Cooperative Sadian Pragmatics Principle in Communication. I further recommend to study the non-cooperative principle in business communication where it could be observed more frequently the non-cooperative principle in communication between party $\mathrm{A}$ and party $\mathrm{B}$, and in the education system between students and teachers, or in the relationship between patients and personal medicals, and in many other situations.

\section{References}

Bultinck, B. (2005). Numerous Meanings: The Meaning of English Cardinals and The Legacy of Paul Grice, Belgium: Antwerp University Association.

Grice, H. P. (1989). Studies in the Way of Words: Logic and Conversation, London: Harvard University Press/Cambridge/Massachusetts.

Grice, H. P. (1969). Utterer's Meaning and Intention, The Philosophical Review, 78(2), 147-177.

Grice, H. P. (1957). Meaning. The Philosophical Review, 66(3), 377-388.

Hadi, A. (2012). A Critical Appraisal of Grice's Cooperative Principle. Open Journal of Modern Linguistics, 3(1), 69-72. http://dx.doi.org/10.4236/ojml.2013.31008

Sobhani, A., \& Saghebi, A. (2014). The Violation of Cooperative Principles and Four Maxims in Iranian Psychological Consultation. Open Journal of Modern Linguistics, 4, 91-99. http://dx.doi.org/10.4236/ojml.2014.41009

Sarangi, S. K., \& Slembrouk, S. (1992). Non-cooperation in communication: A reassessment of Gricean Pragmatics. Journal of Pragmatics, 17, 117-154. http://dx.doi.org/10.1016/0378-2166(92)90037-C 
Biographical notes

Sadi Patrick Makangila is a Ph.D. candidate at Central China Normal University taking up a major in English Language and Literature, specializing in Translation. He graduated from the University of Kinshasa and earned his master degree in Translation and Interpreting from Central China Normal University, China in 2017. He has published one literary book in Chinese, and already published three research papers in Applied Linguistics, Literature and Translation.

Yesdauletova Sabira is a Ph.D. candidate at Central China Normal University taking up a major in Foreign and Applied Linguistics. She graduated from Kazakh Natioanal Pedagogical University named after Abai, earned her MA degree in pedagogical science in 2015.

\section{Copyright Disclaimer}

Copyright for this article is retained by the author(s), with first publication rights granted to the journal.

This is an open-access article distributed under the terms and conditions of the Creative Commons Attribution license (http://creativecommons.org/licenses/by/3.0/). 